\title{
Attitudes Towards Science: a case study of the students at the Second Chance School, Domokos prison, Greece
}

\author{
Georgios Giannoukos \\ Remos Armaos \\ Hellenic Open University, Greece
}

\begin{abstract}
This paper researches the attitudes of the inmates attending the Second Chance School, Domokos prison in Greece, towards the Sciences with the help of the research scale, Attitudes Towards Science (ATS). The research took place from 3rd to 6th February 2014. Thirty eight inmate students, from different countries, aged 21 to 45 who were enrolled in the $1^{\text {st }}$ and $2^{\text {nd }}$ year of the Second Chance School were the subject of the study, the results of which revealed positive attitudes towards science.
\end{abstract}

Keywords: Adult education, prison education, scientific literacy, second chance school

\section{Introduction}

Second Chance Schools (SCSs) are aimed at people who have reached the age of 18 and have not completed the nine-year compulsory education. SCS certificate is provided after successfully in completing twoyears of study. The purpose of SCSs is to be able to offer training to people who, for various reasons, left education so they can gain confidence (European Commission - White Paper, 1996). The SCS belonging to a European project that aims to combat social exclusion. The Adult learners that attend SCSs are educated to be literate in different subjects one of which is to be scientifically literate.

\section{Education in prison}

The belief that incarceration should not only serve to purpose of isolation of dangerous people from society but also should have a role in educating both social and moral order to help reintegrate these people into society, began in the $19^{\text {th }}$ century. That is, it should have a more humanitarian purpose in order to give the opportunity for prisoners to be rehabilitated and reformed. The penalty of imprisonment is often not enough 
to prevent a future recurrence, so the time spent in prison should be used as constructively as possible for the best possible outcome in addressing factors that affect the chances of recidivism in delinquency. Education is a key factor that helps to combat social exclusion by providing the opportunity for students in prison to change their personal attitudes and perceptions and even to acquire skills and knowledge. Moreover in accordance with international conventions (United Nations, 1948), access to education is a right of every human being and therefore the inmates have the same right to education. Article 14 of the Charter of Fundamental Rights of the European Union states that every person has the right to education and access to vocational and continuing training. Also in 1990 the Recommendation on Education in Prisons adopted by the Council of Europe and the education of inmates in EU countries, specifically referred to in Article 28 that ensuring access of prisoners to education and training is the duty of every correctional facility services and politicians will have to guarantee this right (Council of Europe, 1990).

Important studies (Nuttall, Hollmen \& Staley, 2003) demonstrate the effectiveness of education in prison aimed at reducing delinquency. According to Linton (2004) approximately $60 \%$ of former prisoners in the USA end up back in prison, while other research suggests that the rate of recidivism for inmates educated in the USA ranges from 15\% -30\% (Slater, 1995). Chappel (2002) concludes that the higher the level of education of the inmates the smaller the chance of them reoffending.

\section{Profile of the inmate learners}

Though the prison population is heterogeneous, surveys show that there are common characteristics among prisoners (Visher and Travis, 2003), and are as follows:

- $\quad$ Prisoners generally have low levels of education. Research shows that $53 \%$ of prisoners are illiterate in Ireland (Morgan and Kett, 2003).

- A high percentage of prisoners have not completed compulsory education because of negative past educational experiences. Research in the Netherlands showed that $27 \%$ of people leaving education of an early age were suspected of crimes compared with $7 \%$ of those who completed compulsory education. (Ministry of Education, Netherlands, 2010).

- $\quad$ Many of the prisoners have learning difficulties (Moeller, Day \& Rivera, 2004).

- Many prisoners come from dysfunctional families of which a member is or was in prison (Johnson \& Waldfogel, 2004).

- $\quad$ Lack of stable employment in the past or poor working conditions (Austin \& Hardyman, 2004). 
- A high proportion of prisoners have a history of substance abuse (Pelissier, 2004).

- $\quad$ Many of the prisoners have mental health problems (Blaauw, Ronald \& Kerkhof, 2000).

- $\quad$ They have reduced confidence and strong feelings of failure and anxiety (Winters, 1997).

\section{The concept of scientific literacy}

The term science in England historically refers to the physical sciences and by extension, the term scientific literacy refers to the physical sciences too. But in recent years this term includes the words 'technology' and 'mathematics', as applications in the physical sciences. American researchers use the term 'scientific literacy' but in England the term 'public understanding of science' is used (Laugksch, 2000).

It is interesting to see the different views that exist on this term. According to Gallagher \& Harsch (1997) this term is over forty years old, but with different definitions over the years. It first appeared as a term in 1958 by Paul DeHart Hurd in his article entitled Science Literacy: Its Meaning for American Schools (Laugksch, 2000). The Hurd used the term to describe society's understanding of both the sciences and its applications. According to Durant (1993) scientific literacy refers to the general knowledge a person has about science and understanding of scientific ideas. Norris \& Philips (2003) argue that the term has been used to include some knowledge, abilities and skills a person should have in order to be able to:

- $\quad$ distinguish science from non-science

- $\quad$ understand scientific applications

- $\quad$ think in a scientific way

- $\quad$ use the scientific method to solve problems

- $\quad$ recognize the benefits and risks of science

- $\quad$ recognize the nature of science and its relationship with culture.

- $\quad$ think critically in science

It is difficult to give a specific definition of scientific literacy, as well as being difficult to separate it from technological literacy, which connects science and technology in everyday life. According to Unesco (1993) someone who is scientifically and technologically literate can function in society as a whole rather than as a scientist in a scientific workplace. According to Durant (1993) scientific literacy is what the general public need to know about science, while Millar (1997) argues that to be a functional citizen in society one should be scientifically literate, but Laugksch (2000) considers that the term scientific literacy refers to the knowledge someone needs to have of science to appreciate the purpose of science and understand basic scientific ideas. Hazen (2002) considers that 
scientific literacy is a mixture of concepts, history and philosophy that helps us to understand the scientific issues of our time. Rychen \& Salganik (2003) argue that scientific literacy is necessary for the development of skills in the rapidly growing technological era we live. Klein (2006) believes that scientific literacy refers to the ability one has to have to be able to read scientific articles.

Therefore, it is clear that there are many definitions of scientific literacy. According to Shamos (1995) there are three basic categories of definitions. The first refers to a mixture of scientific knowledge and concepts with elements of history and philosophy someone should have so as to be able to read scientific articles and follow scientific discussions, and is known as cultural scientific literacy. The second category known as functional scientific literacy refers not only to knowledge of scientific concepts someone should have, as required by the previous category, but also the ability one should have to be able actively communicate with others scientifically. Finally, the third category, true scientific literacy goes beyond the knowledge of the previous two categories and includes the knowledge and the ability someone should have in order to be able to formulate scientific questions and develop inductive and productive thinking also knowing fundamental scientific theories. The latter, true scientific literacy, is the most difficult to achieve.

\section{Research methodology}

Our research was conducted on adult male learners at SCS Domokos prison who are enrolled in year 1 and 2 of secondary school. In our sample, the ages of students range from 22-44 and country of origin varies students being from countries in Europe, Africa and Asia. To research the attitudes of learners of SCS Domokos prison towards Science the Attitudes Toward Science Scale (ATS) of Francis \& Greer (1999) was chosen. Specifically ATS contains 20 statements based on a 4-point Likert scale (strongly disagree $=1$ - disagree $=2$ - agree $=3$ - strongly agree $=4$ ). According to Francis \& Greer (1999) these 20 statements were selected from a total of 62 questions related to the physical sciences, which are both behavioural and constructive in nature. One of the statements was not included in our research because it is not appropriate for our sample, namely number 18 which was in the original questionnaire and says "I'd seriously consider becoming a scientist when I finish school '. Therefore our ATS questionnaire has a total of 19 statements. Note here also that statements 5 and 17 in the original questionnaire mentioned the USA and specifically stated as "Science is very important to the future of the United States" and "the United States needs to have many more scientists', respectively. For the needs of our research we generalized those statements by rephrasing them as "Science is 
very important to the future of a country" and "Every country needs to have many more scientists', respectively. The reason why we generalized these two statements is that the population of our sample comes from different countries.

\section{Conducting the research}

The final distribution of the questionnaire was preceded by a pilot questionnaire of six students at SCS Domokos prison, 3 from first year level and 3 from the second. The selection of these learners was made randomly and the pilot questionnaire was distributed by the researcher. Then after correcting errors in the questionnaire, it took its final form and was distributed to learners by the researcher from February 3, 2014 to February 6, 2014. A total of 40 questionnaires were given out by the investigator 38 of which were completed.

\section{Issues of ethics}

The research complied with ethical requirements, any information that needed to be used for reporting and the preparation of this work is referred to both in the research paper and the bibliography. The students took part in this research at their own will, none of them was forced to participate, and all of them had been previously informed by the researcher about the study and its objectives. The questions were such so as not to offend the participants and not lead to a decrease in self-esteem. Also there was no attempt to change their attitudes towards science. The study was conducted in such a manner so as not to create stress and / or fatigue to the participants. All students who took part in the study received the same treatment and the same respect from the researcher and participation was anonymous.

\section{Results and Discussion}

The demographics of the questionnaire showed that of the 38 people who completed the questionnaire, 11 are aged 21-24, 15 are aged 26-30, 7 are from 31-35 years old, 4 are from 36-40 years old, while 1 person is 44 years old. 17 of these students are enrolled in the 1st year and the remaining 21 in the 2nd year of secondary school.

In the first statement which says that if science has ruined the environment, 3 people strongly disagreed, 14 disagreed while 11 and 10 agreed and strongly agreed respectively. We observe that most consider science responsible for destroying the environment. The next statement of the questionnaire, states that science is taught in school is fun and interesting, 17 said that they agreed and 21 strongly agreed. This result is interesting because all respondents seem to find this literacy interesting. 
Concerning the statement whether science is relevant to everyday life we see that the majority replied positively, namely 14 said that they strongly agreed and 21 agreed while only 3 disagreed. The majority of respondents agreed the statement about whether science is very important to the future of a country. More specifically, 14 strongly agreed, 23 agreed and only 1 disagreed.

The results of the sentence stating that science is a difficult subject to learn as of interest as here the majority of respondents agreed. More specifically, 16 strongly agreed, 17 agreed while 4 disagreed and 1 strongly disagreed. Regarding statement whether money spent on science is well worth spending, 10 respondents strongly agreed, 20 agreed and 8 disagreed. We observe that most of them express a positive view on the subject. As for the statement whether science will help to make the world a better place in the future, most respondents answered positively, namely 11 strongly agreed, 21 agreed, 5 disagreed and 1 strongly disagreed. The results of the statement referring to whether science discoveries do more harm than good, showed that the percentage who responded positively are about the same as those who replied negatively (Figure 1).
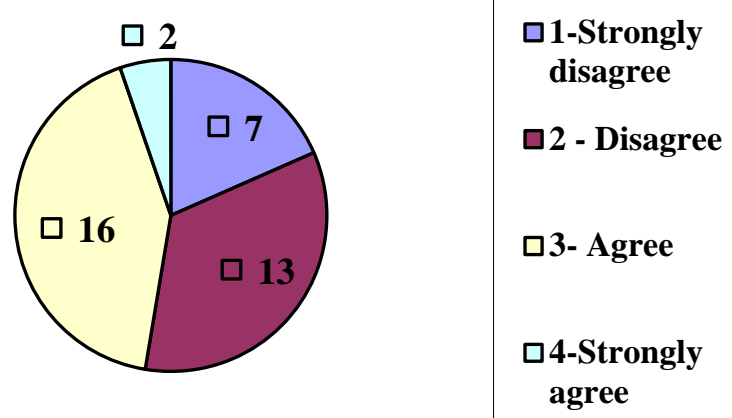

Fig.1: Science discoveries do more harm than good.

The answers to the statement referring to whether science and technology are the cause of many of the world's problems are of interesting. Most students agreed with this statement. Specifically 12 strongly agreed, 18 agreed and only 5 disagreed and 3 totally disagreed. 18 strongly agreed, 16 agreed and only 4 disagreed with the statement that each country needs to have many more scientists. Students responses here shows that the majority feel every country needs scientists and science in contrast with their response to the previous which showed they believe that science is the cause of many world problems. 


\section{Conclusion}

The results show that the students of SCS Domokos prison appear, on the whole, to find scientific literacy taught in school enjoyable and interesting. This result agrees with other studies conducted in schools in various countries, such as those by Beaton, Mullis, Gonzalez, Smith, \& Kelley (1996) where 78\% of students in England, 93\% in Iran, 92\% in Singapore, 90\% in Thailand, 89\% in Kuwait said they like science. A survey conducted in 2006 in New Zealand, showed similar results where 71\% of students agreed that they like learning about science (OECD, 2007). Research conducted by the Institute of Electrical Engineers (The Research Business, 1994) in England showed that 68\% of students felt that science is helpful while 58\% that it is interesting.

92\% of the students at SCS Domokos prison agreed with the proposal that science is relevant to everyday life. Here we observe that this result is consistent with similar studies conducted in several countries, such as in research conducted in England in 1994, in which $87 \%$ of students said that science is important in everyday life (The Research Business, 1994), while a survey in Japan in 1995 (Prime Minister's Office, 1995) showed 91\% of respondents believe that science is important in everyday life. Another survey conducted in England in 2011 shows that 82\% of respondents believe that science plays a very important role in our lives (Ipsos Mori's Social Research Institute, 2011).

87\% of learners in SCS Domokos prison agreed that employment in a science lab would be an interesting job. This result coincides with that of the research done in England in 2011 (Ipsos Mori's Social Research Institute, 2011) which showed that $68 \%$ agreed that a science related job would be very interesting. In the questionnaire statement stating that science is a difficult subject to learn, $86 \%$ of our survey respondents agreed. Research conducted in England in 2010 revealed similar results, where only 3\% of students agreed that science is an easy subject (Opinion panel, 2010).

The results about whether the money spent on science is worth spending are of interest. $79 \%$ of respondents in our survey agreed that this money is worth spending. Similar results emerged from research done in England, where 76\% agreed that such investment should be made even if the benefits are not immediate (Ipsos Mori's Social Research Institute, 2011). In our research 52\% disagreed with the suggestion that the discoveries of science do more harm than good, while the remaining $48 \%$ agreed. Here we observe that there is an almost equal distribution between positive and negative views. In this statement our research agrees with the results of other studies, such as these carried out in England (Ipsos Mori's Social Research Institute, 2011) in which 54\% of respondents agreed that the good effects outweigh the bad, which differs slightly with a corresponding survey 
conducted in Japan (The National Institute of Science and Technology Policy, 2001) which showed that $64 \%$ believed that the positive effects of science outweigh the negative.

\section{References:}

Austin, J. \& Hardyman, P. (2004). The risks and needs of the returning prisoner population. Review of Policy Research, 21(1), 13-29.

Beaton, A., Martin, M. O., Mullis, I., Gonzalez, E. J., Smith, T. A., \& Kelley, D. L. (1996). Science Achievement in the Middle School Years: IEA's Third International Mathematics and Science Study. Chestnut Hill, MA: Boston College.

Blaauw, E., Ronald R., and Kerkhof, A. (2000). Mental Disorder in European Countries. International Journal of Law and Psychiatry, 23(5-6): 649-663.

Chappell, C.A. (2002). Post-secondary correctional education and recidivism: A meta-analysis of research conducted 1990-1999. The Journal of Correctional Education, 55(2), 148-169.

Council of Europe, (1990), Education in prison. Recommendation No. R (89) 12 adopted by the Council of Ministers of the Council of Europe. Strasbourg: Council of Europe.

Durant, J. R. (1993). What is scientific literacy? In J. R. Durant \& J. Gregory (Eds.), Science and culture in Europe (pp. 129-137). London: Science Museum.

European Commission, (1995), White Paper on education and training. Teaching and learning. Towards the learning society.

Francis, L. J., \& Greer, J. E. (1999). Measuring attitude towards science among secondary school students: The affective domain. Research in Science and Technological Education, 17, 219-226.

Gallagher, J., \& Harsch, G. (1997). Scientific literacy: Science education and secondary school students. In W.Graeber \& C. Bolte. (Eds.). Scientific literacy: An international symposium (p. 13-34). Institut für die Pädagogik der Naturwissenschaften (IPN): Kiel, Germany.

Hazen, R. (2002). Why Should You Be Scientifically Literate? American Institute of Biological Sciences. Retrieved October 31, 2013, from http://www.actionbioscience.org/education/hazen.html\#prime

Ipsos Mori's Social Research Institute (2011). Public Attitudes to Science, Summary Report. London: Ipsos Mori.

Johnson, E. \& Waldfogel, J. (2004). Children of incarcerated parents: Multiple risks and children's living arrangements. In Western, B., Lopoo,L. \& McLanahan, S. (Eds.), Imprisoning America: The social effects of mass incarceration (pp. 97-134). New York: Russell Sage Foundation. 
Klein, P.D. (2006). The challenges of scientific literacy: from the viewpoint of second-generation cognitive science. International Journal of Science Education, 28(2-3), 143-178.

Laugksch, R. C. (2000). Scientific literacy: A conceptual overview. Science Education, 84(1), 71-94.

Linton, J. (2004). U.S. department of education update. The Journal of Correctional Education, 55(4), 274-276.

Millar, J. (1997). Civic scientific literacy in the United States: A developmental analysis from middle school through adulthood. In: W. Graeber \& C. Bolte (Eds.), Scientific literacy: An international symposium (p. 121-142). Institut für die Pädagogik der Naturwissenschaften (IPN): Kiel, Germany.

Ministry of Education, Culture and Science. (2010). The approach to school drop-out: Policy in the Netherlands and the provisional figures of the 2008 2009 performance agreements, Netherlands.

Moeller, M., Day, S. \& Rivera, B. (2004). How is education perceived on the inside?: A preliminary study of adult males in a correctional setting. The Journal of Correctional Education, (55)1, 40-59.

Morgan, M, Kett, M. (2003). The Prison Adult Literacy Survey, Results and Implications. Dublin: Irish Prison Service.

Norris S.P., \& Phillips, L.M. (2003). How literacy in its fundamental sense is central to scientific literacy. Science Education, 87, 224-240.

Nuttall, J., Hollmen, L. \& Staley, E. (2003). The effect of earning a GED on recidivism rates. The Journal of Correctional Education, 54(3), 90-94.

OECD (2007). PISA 2006: science competencies for tomorrow's world, vol. 1: analysis. Paris: OECD.

Opinion Panel (2010). Report for Department for Business, Innovation and Skills: Attitudes to Science. London: Opinion Panel.

Pelissier, B. (2004). Gender differences in substance use treatment entry and retention among prisoners with substance use histories. American Journal of Public Health, 94(8), 1418-1424.

Prime Minister's Office (1995). Public Opinion Survey of Relations of Science and Technology to Society. Survey taken in February 1995. S\&T Today 14(6):12. Tokyo: Japan Foundation of Public Communication on Science and Technology.

Rychen, D.S. \& Salganik, L.H. (Eds.). (2003). Key competencies for a successful life and a well functioning society. Cambridge, MA: Hogrefe \& Huber.

Shamos, M. H. (1995). The myth of scientific literacy. New Brunswick, NJ: Rutgers University Press 
Slater, R.B. (1994-1995). Locked in but locked out: death sentence for the higher education of black prison inmates? The Journal of Blacks in Higher Education, No.6, 101-103.

The National Institute of Science and Technology Policy (2001). Science and Technology Indicators: 2000. A Systematic Analysis of Science and Technology Activities in Japan. Tokyo: Science and Technology Agency. The Research Business (1994) Views of Science Among Students, Teachers and Parents. London: Institution of Electrical Engineers.

United Nations (1948). Universal Declaration of Human Rights, G.A. res.217A (III), U.N. Doc A/810 at 71.

United Nations Educational, Scientific and Cultural Organisation. (1993). Final Report: International forum on scientific and technological literacy for all. Paris: UNESCO.

Visher, C. \& Travis, J. (2003). Transitions from prison to community: Understanding individual pathways. Annual Review of Sociology, 29, 89113.

Winters, C. (1997). Learning Disabilities, Crime Delinquency and Special Education

Placement. Adolescence (32): 451- 462. 